\title{
O que é Educação Física? Uma
}

\section{abordagem curricular}

Gabriel H. Munoz Palafox*

Depois de ler os artigos que tratam sobre o tema Afinal, o que é Educação Física? da revista Movimento $\mathrm{n}^{\circ} 1$ e 2 , decidi contribuir com o debate, devido ao fato principal de que a diversidade das análises começa a crescer e misturar-se com algumas argumentações desprovidas de uma fundamentação filosófica consistente, como é o caso do artigo apresentado pelo Dr. $\mathrm{H}$. Lovisolo.

Analisando os artigos de Bracht, Santin e Ghiraldelli Jr., verificamos que, em momento algum, é demonstrada qualquer tipo de preocupação ética relacionada com as críticas que Escobar e Taffarel fazem às idéias do Dr. Gaya.

Com uma definida e muito conhecida postura política e científica, as autoras preocupam-se com a essência do discurso de Gaya e defendem, adequadamente, um marco teórico que hoje é referência fundamental no campo da produção de conhecimento na Educação Física.

Não vou deter-me neste espaço a fundamentar a crítica que faço ao artigo do Dr. Lovisolo, pois considero que os esforços teóricos de Escobar e Taffarel, Bracht, Santin e
Ghiraldelli Jr. são corretos. O que precisamos é avançar em torno da pergunta central do debate.

Para tanto, analiso a questão tomando como referência as idéias desses autores dentro do contexto da formação profissional: o planejamento de currículo à luz das teorias críticas da Educação.

Nos artigos dos autores citados, parece existir o consenso de que a Educação Física é uma atividade humana (Marx) e manifesta-se como uma prática social.

Analisando essa prática social dentro de nosso enfoque de estudo, verifico que, de acordo com os interesses políticos e pedagógicos em jogo, a Educação Física pode enfatizar um caráter formativo de amplo impacto sóciocultural (cidadãos educados e conscientes de seu papel histórico-social, em função de uma determinada perspectivade classe) e/ou, restrito, quando se manifesta na forma de instrução ou treinamento de determinadas habilidades e/ou hábitos comportamentais de ordem motora, moral ou higiênicoterapêutica.

Quando a finalidade da organização curricularé direci- onada ao campo restrito de formação e se desconsidera a importância da reflexão sobre o impacto político-pedagógico do processo, dos procedimentos de e n s i no - a p re ndi z a g e m utilizados, assim como da interação social entre os atores do mesmo (autoridades, professores e alunos), estes deixam de ser sujeito (no sentido marxista da palavra), para tornarem-se a1vo das implicações ideológicas do "currículo oculto" subjacente, de caráter reprodutor e alienante, ligado a estruturas intersubjetivas de dominação cultural ${ }^{1}$.

Por outro lado, a Educação Física tem, de fato, um caráter normativo e conta pára sua efetivação, com um c o n g $10 \mathrm{merado}$ d e conhecimentos que são produzidos, organizados e sustentados por enfoques científicos de cunho empíricoanalítico, his-tóricohermenêutico e/ou praxiológico, com base no Materialis-mo Histórico.

$\mathrm{Na}$ Educação Física (assim com em outras práticas educacionais), o conhecimento produzido através dos cientistas e/ou filósofos da área, explícita ou implicitamente, sustenta, nas suas obras, visões de homem, mundo, sociedade e formas de interação humana 
que refletem, direta ou indiretamente, uma forma de organização sócio-políticoeconômicadeterminada.

Por esses motivos, dentre outros, a Educação Física aparece não como uma prática social única e restrita, e sim como várias práticas sociais de caráter político-pedagógico, corporificadas na forma de propostas de ensino e/ou de treinamento de habilidades, com seus próprios interesses e fontes de análise filosófica, científicae pedagógica.

Essas fontes, além de tematizar elementos da esfera d e nos s a c u $1 \mathrm{tur}$ a corpora $1 /$ movimento manifestados através do jogo, do esporte, da ginástica e da dança (Taffare1 Castellani Filho; Bracht), apresentam-se também como campos em disputa por uma hegemonia política, instrumental e teórica. Daí sua estreita ligação com a busca de poder nas estruturas normativas de caráter institucional que regulam as formas de organização, a d m i n i s t r a ç ã o e , principalmente, os critérios de distribuição de recursos financeiros para sustentação de projetos político-pedagógicos e/ ou de pesquisa.

Essas estruturas são e deveriam ser, oficialmente. parte do objeto específico de estudo da Educação Física, pois, na prática, não são separadas do campo restrito de atuação do professor, já que este depende em grande parte das condições e políticas emergentes dessas estruturas, e vice-versa, para sua correta efetivação.

Na verdade, todos esses aspectos refletem a tentativa de explicar como a Educação Física se manifesta na realidade concreta, realidade esta que, quando fragmentada, termina sendo reificada na nossa cons- ciência (Berger e Luckmann), c o m a s u b s e qü e n t e incapacidade de vislumbrar as condicio-nantes históricas que a determinam.

Assim, na perspectiva curricular, o professor de Educação Física não é simplesmente um agente pedagógico: ele é um agente político-pedagógico que deve ser capacitado com bases filosóficas, científicas e pedagógicas suficientes para poder "dar conta" não somente de seu fazer restrito (aula), mas também das ações concretas que são necessárias para defender, conscientemente, seu projeto de educação e sociedade.

Se o professor encontrase fora do alcance dos conhecimentos e da prática social necessária para compreender como ele, enquanto profissional e c idadão, constrói-s e historicamente para situar-se no mundo, dificilmente poderá tomar consciência sobre por que determinadas "coisas" ou fenômenos acontecem na sua área de atuação e muito menos poderá ser capaz de propor alternativas para transformar sua realidade de trabalho com base num projeto coletivo de sociedade mais justa, humana e democrática.

Por todos esses componentes, desde o ponto de vista da Teoria Crítica do Currículo Educacional, entendo que a Educação Física pode ser considerada uma Ciência sim (não da Motricidade Humana nem da Saúde). Ela é uma CIÊNCIA DA EDUCAÇÃO que superou epistemologicamente sua fase pré-paradigmática e precisa de uma adequada organização curricular em que possam ser confrontados os diferentes campos de reflexão, capacitação docente e atuação profissional em condições d e disputa equilibrada para poder en- contrar seu verdadeiro sentido/ significado social.

Como vivemos numa sociedade capitalista em que se privilegiam intencionalmente projetos político-pedagógicos para sustentação dos interesses e do status já alcançado por certas classes sociais, sabe-se que a busca desse equilíbrio é desigual, pois, como para essas classes existe a necessidade de manter os espaços de poder institucional onde se legitimam tais privilégios, além das vantagens financeiras conquistadas, aproveitam-se do controle dos meios de comunicação de massa para reforçar as práticas de convencimento inter-subjetivosimbólico-estruturador para manutenção do sistema de vida atual.

Isso significa dizer que toda proposta pedagógica colocada em prática reflete, apesar daqueles que não acreditam mais, a luta de classes, que já foi bem explicitada por Marx e seus contemporâneos, incluindo 0 próprio Habermas (atualmente moda no contexto da Educação Física) ${ }^{2}$.

Assim, tomando como referência 0 acima exposto e pegando uma carona em Bracht e Santin. procurarei apresentar o resultado de um "exercício" filosófico para colocar alguns dos aspectos constitutivos (ônticos) da Educação Física, que, depois de analisados, poderão ajudar-nos a compreender melhor, dentro de uma perspectiva curricular, afinal, o que é Educação Física.

Co mo já for apresentado, viu-se que a Educação Física é uma atividade humana. Manifestasse no condensado social através de práticas sociais com interesses e enfoques filosóficos, científicos e pedagógicos diferenciados, que podem ser 
analisados epistemologicamente em decorrência das visões, explícita ou implicitamente, colocadas sobre o homem, o mundo e a sociedade.

Organiza-se mxm\&estrutura curricular, pois trata-se de um conjunto de conhecimentos advindo dos campos das Ciênci-as Humanas, Naturais e Exatas, utilizado para subsidiar e atualizar, em caráter interdisciplinar, os seguintes aspectos:

diferentes temáticas advindas da cultura corporal, que constituem o seu corpo de conhecimentos ${ }^{3}$;

formação filosófica e científica do professor; e

ação profissional do professor na realidade concreta ${ }^{4}$.

A ação profissional do professor de Educação Física concretiza-se através do estabelecimento de um processo de interação e comunicação social mediatizado pela relação ensinoaprendizagem e pela aplicação de procedimentos de ensino, que podem ser vinculados a ações problematizadoras de caráter amplo (formação para a cidadania) e/ou restrito (tecnicismo), como é o caso do treinamento de habilidades específicas.

A Educação Física é uma prática política que não é neutra e reflete concepções simbolicamente criadas e estruturadas para sustentar, conscientemente ou não, um determinado modelo de sociedade que, por sua vez, favorece a presença das várias práticas existentes na realidade, como são os casos daqueles professores que por " $n$ " fatores se limitam diariamente, na escola, a entregar a bola aos alunos e esperar o final da aula, ou daqueles que ministram aulas de ginástica aeróbica correndo de academia em academia e concorrendo com os outros em função da performance técnica, para poder garantir o emprego.

Nesse sentido, a busca de inserção da Educação Física em projetos sociais ligados à procura de superação do modelo capitalista requer, dentre outros aspectos, a estruturação de processos curriculares comprometidos efetivamente com essa tarefa. Uma coisa é formar profissionais capazes de interferir na realidade social segundo a orientação instrumental dada pela capacitação profissional (Ex.: médico de comunidade ou pesquisador, segundo o Dr. Lovisolo), e outra, inserir criticamente toda essa orientação num campo de atuação politicamente contestado, a começar pelo próprio modelo de sociedade.

Em síntese, não basta formar educadores que simplesmente saibam por que, como e onde fazer. Eles também precisam aprender e conhecer, polí-tico-pedagogicamente, a favor de quem e contra quem servem (como bem gosta de dizer Gadotti), para poder alcançar sua efetiva emancipação individual e social.

Finalmente, gostaria de mencionar que profissionais como Escobar e Taffarel sabem disso e, longe de serem idealistas, são pessoas que têm clareza objetiva do projeto histórico de sociedade que defendem. Sabem perfeitamente que estão inseridas num contexto de vida que procura manter os privilégios de poucos em detrimento da maioria e, há m u i tos a nos, vê m implementando coletivamente uma proposta filosófica e político-pedagógica para a Educação Física escolar que não é mais um sonho; é uma realidade que, a cada dia que passa, afirma-se mais e mais de forma crítica, como alternativa viável de contribuição para a emancipação da classe trabalhadora, da qual faz parte a categoria dos professores de Educação Física.

\section{NOTAS}

1 Adepto da Filosofia liberal, Ralph Tyler fez isso nos Estados Unidos da América, com a ajuda das Ciências Humanas e Naturais de base empírico-analítica e ter minou criando seu sistema de planejamento, denominado técnico-linear pelos estudiosos da Teoria do Currículo.

2 Para Habermas, quando não existem condições objetivas para o estabelecimento de uma ação comunicativa de caráter consen sual com finalidades emancipatórias entre os indivíduos, e a argumentação discursiva é ex cluída do processo, torna-se necessário estabelecer ações es tratégicas (como é o caso da luta de classes) para superação do caráter autoritário, conservador e repressivo das instituições da sociedade moderna.

${ }^{3}$ Para aprofundamento das com petências interativas e comunicativas que devem ser alcançadas através do Ensino da Educação Física, consultar KUNZ, E. (1994). Transformação didático pedagógica do esporte. Ijui: Inijui. Para estudo dos ciclos de escolarização necessários para refletir em torno da organização e tratamento dos conteúdos da Educação Física no contexto es colar, consultar COLETIVO DE AUTORES (1994). Metodologia do ensino da Educação Física. $2^{\mathrm{a}}$ Edição. São Paulo: Cortez.

${ }^{4}$ Abordei esse assunto no artigo As tendências pedagógicas da Educação Física e sua relação com as categorias idealista e materialista da História, publi cado na Revista Motrivivência. Ano VI, n ${ }^{\circ}$ 4, junho de 1993. Nesse trabalho, ainda que publi cado com severas alterações ao texto por motivos técnicos alhei os aos coordenadores da edição, mencionei que a ação do profes- 
sor de Educação Física deve ser projetada para atuar dentro de três esferas, intimamente ligadas entre si: a) a aula vinculada ao desenvolvimento da personalidade do ser social, num ambiente onde a riqueza cultural estabeleça-se como trampolim para a crítica; b) a pesquisa científica; e c) a prática social, da qual dependem as outras duas, como, por exemplo, a luta de classes em defesa da implementação de projetos diferenciados de Educação, Educação Física e Esporte.

\section{UNITERMOS}

Educação Física - Educação Currículo

Gabriel H. Munoz Palafox é Mestre em Educação: Supervisão e Currículo pela PUC-SP. Membro pesquisador do Colégio Brasileiro de Ciências do Esporte. 